\title{
VOCES CON CAUDAL, DE CARLOS ENRIQUE CABRERA
}

\section{José G. Guerrero}

Historiador, profesor de la Universidad Autónoma de Santo Domingo (UASD) y del Instituto Tecnológico de Santo

Domingo (INTEC), República Dominicana.jose.guerrero@intec.edu.do

Cómo citar: Guerrero, J. G. (2018). Voces con caudal, de Carlos Enrique Cabrera. Ciencia y Sociedad, 43(2), 97-99. doi: http://dx.doi.org/10.22206/cys.2018.v43i2.pp97-99

Voces con caudal es la obra más reciente de Carlos Enrique Cabrera, un distinguido intelectual y profesor universitario dominicano con estudios de licenciatura y de maestría en la Universidad Autónoma de Madrid (España). En esta obra se reúnen entrevistas y crónicas de 17 autores y artistas dominicanos y extranjeros, publicadas entre 2002 y 2009 en la revista Caudal, dirigida por él. Los autores entrevistados describen el proceso de creación de su trabajo intelectual y también dejan oír sus voces y sus quejas.

La entrevista es un género dialógico entre dos o más personas. A diferencia del diario y la carta, que son personales e íntimos, la entrevista enlaza lo social y lo individual con placer e inteligencia. La entrevista auténtica provoca y el entrevistado acepta la provocación. Por eso siempre se puede salir de las manos. En nuestro país, la entrevista es un género desaparecido u olvidado, si es que llegó a existir. Es como si a nadie le interesaran los autores de las obras, como si estas se hicieran solas, por generación espontánea, caídas del cielo, sin dolor o alegría, sin pena ni gloria.

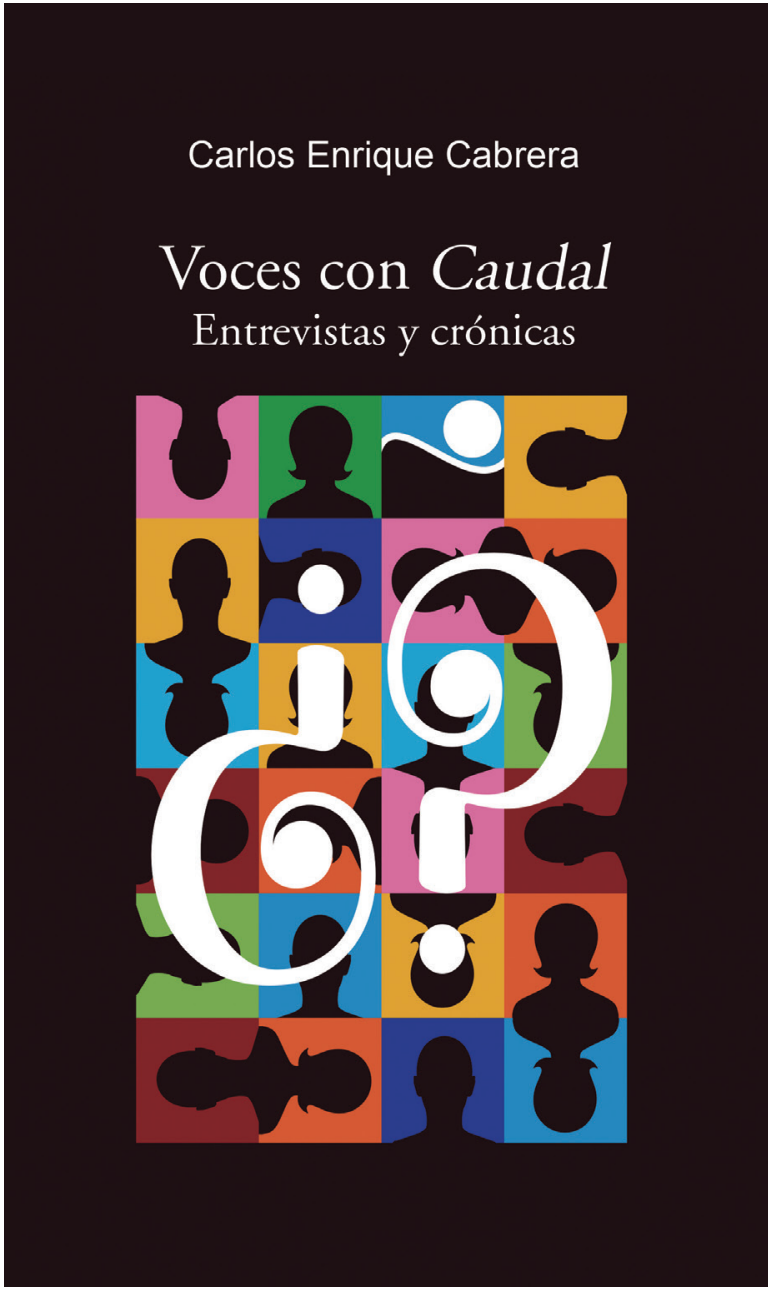


La falta de entrevistas profundas e inteligentes también es fruto de la tremenda hipocresía y multiplicidad de máscaras - personas, en latín-con las que vivimos los dominicanos: un país básicamente de afrodescendientes que se consideran indios, el pueblo más feliz en medio de una gran pobreza, país que dice vivir una revolución educativa, sin embargo, ocupa el último puesto en su prueba Pisa y además mantiene cerrada una institución tan importante para la comprensión de la propia identidad y su realidad: el Museo de Historia y Geografía. No vivimos una época positiva. La nuestra es esencialmente trágica, como dijo D. H. Lawrence; mientras para Giles Lipovetsky es la era del vacío, de lo efímero y de la cultura como mercancía. En el país hemos llamado a los positivistas Eugenio María de Hostos, José Ramón López, Américo Lugo y Francisco Moscoso Puello "creadores del pesimismo dominicano" porque confundimos realismo con positivismo.

Tomo prestado el título de una maravillosa obra de Camila Henríquez Ureña para hacer una invitación a la lectura de Voces con caudal, de Carlos Enrique Cabrera. Ya la obra, en su conjunto, dejó de pertenecerle y es el público quien decidirá si tendrá vida o no. Advierto al lector que puede encontrarse con alguna frase o posición de los entrevistados algo indigesta. La entrevista es antípoda del maquillaje. Se pueden notar muchos puntos en común, sin importar que los entrevistados sean nacionales o extranjeros, artistas, literatos o científicos.

Carlos es buen intelectual y mejor amigo. A los buenos amigos hay que aguantarles las bromas pesadas -frescuras, en dominicano-. Aquí estoy yo, comentando su libro, que comienza con una entrevista a mi propia persona. Los retóricos grecolatinos recomiendan un discurso epidíctico o elogioso en un momento tal. No le haré una mala jugada ni lo que Carlos Marx le hizo a Bruno Bauer y sus consortes: la crítica a la crítica crítica. Advierto que la palabra crítica significa en griego juez, enjuiciar, no es algo necesariamente negativo. Desde el primer número de Caudal, supe que la revista iba a hacer historia en un medio intelectualmente hostil. Su autor se parecía a Sísifo, el titán griego condenado a cargar permanentemente una enorme piedra hasta la cima de una montańa, la cual cae y la vuelve a recoger. Carlos Enrique Cabrera escribió ingentes editoriales cuyo lema podría ser "crítica o muerte"; hizo estas entrevistas e incluyó crónicas de autores hoy publicadas; trabajó en el diseño y la diagramación y repartió la revista a medios y personas.

Considero un milagro -mirar con asombro, en latín- que la revista Caudal durara siete años, del año 2002 al 2009, entre la debacle financiera y lo que Bernardo Vega llamó el "desguañangue de la economía”. A Caudal le faltó quizás la entrevista más importante, la del mismo autor. Allí nos enteraríamos qué trauma masoquista sufría, qué deuda pagaba o qué apuesta personal hacía con la edición de cada revista. Que Carlos haya recibido una extraordinaria ayuda de su esposa Milagros Fernández no evita compararlo con Sísifo, del cual se pueden hacer dos lecturas: una pesimista (nunca logró empujar la piedra hasta la cima de la montańa) y otra optimista (nunca dejó de cargarla). Los ríos y arroyos se nos cuelan entre las manos, sin embargo, Voces con caudal la tenemos aquí en nuestras manos convertida en libro, lista para ser devorada, como hizo Macunaíma, el héroe brasileńo de Carlos Drumond de Andrade con la cultura, sin importar de dónde viniera.

Es imposible describir sucintamente algún rasgo descrito sobre cada autor entrevistado, sobre todo porque tienen formaciones y vocaciones diferentes entre sí: antropólogos, pintores, literatos, filósofos, feministas, publicistas, cinéfilos, artistas. La diversidad de enfoques en un mundo postmoderno es criterio editorial de este libro. Por suerte, Carlos Enrique Cabrera nos facilita la lectura al identificar en un epígrafe la idea clave de cada autor. Así para José G. Guerrero "el antihaitianismo es el veneno que no nos deja avanzar"; Yuly Monción no tiene patrones ni reglas en su pintura; todo lo que 
hace María Ugarte le divierte; la vocación literaria de Fernando Valerio-Holguín comenzó con una prohibición paterna; para Chiqui Vicioso nada es sagrado ni permanente, sino una realidad a transformar; "para ser escritor hay que apreciar hasta la locura de un hombre", dijo Junot Díaz; para Franklin Knight "la historia de Haití es en parte la historia del sufrimiento del Caribe"; Tomás Eloy Martínez considera que la novela es ante todo un acto de libertad; para Mayra Montero hay una reflexión obsesiva sobre la muerte en todas sus novelas; la literatura es para Sonia Rivera-Valdés el único ámbito donde tiene plena potestad de hacer lo que quiere; según Santiago Roncagliolo, en el trabajo intelectual no sobreviven los mejores, sino los más tercos; para Alonso Sánchez Baute estamos escribiendo la literatura del realismo trágico; a Fernando Savater le gustan los argumentos, pero no los dogmas o las intimidaciones; Guillermo Arriaga trabaja el tema de la muerte para darle su peso a la vida; la literatura de Alfredo Bryce Echenique es una mescolanza endemoniada de rutina y realidad que quiere ser contada; para Nélida Piñón hay que convertir de alguna manera la vida en una aventura personal, en un gran viaje; y, finalmente, Fernando Vallejo cambia un bolero o un tango por cualquier novela. El hilo conductor de todos los autores entrevistados es la relación entre la vida, la creación intelectual y la libertad.
Carlos Enrique Cabrera pondera claramente el objetivo de su libro: divulgar la obra y la figura de las personalidades presentadas, darlas a conocer al gran público y conseguir interesarlo por la lectura (o contemplación) posterior. Son, en definitiva, entrevistas y crónicas, un reclamo, una ventana abierta $o$ un puente a lo que de verdad cuenta e importa aquí: sus obras. El autor hace un apelo al lector y explica lo mucho que se deleitó y aprendió elaborando estos trabajos de periodismo cultural; espera que en el mismo grado "lo hagas tú, amigo(a), lector(a), al leerlos. Ahora, sin más, te pertenecen".

De mi parte, solo me resta felicitar por la publicación del libro al Instituto Tecnológico de Santo Domingo (INTEC), que vive momentos estelares bajo la dirección de Rolando Guzmán, un egresado como yo de la Fundación Getulio Vargas, de Brasil; así como recordarles lo que dije de Carlos Enrique Cabrera cuando presenté su texto Tiempos difíciles: "que es un caudal de agua limpia en medio del pantano".

\section{Referencias bibliográficas}

Cabrera, C. E. (2017). Voces con caudal: entrevistas y crónicas. Santo Domingo: Instituto Tecnológico de Santo Domingo.

Guerrero José, G. (2013). Tiempos dificiles, de Carlos Enrique Cabrera. Ciencia y sociedad, 38(3), 619-628.

\section{Datos de filiación}

José Guillermo Guerrero. Historiador y antropólogo. Estudió en la Universidad Autónoma de Santo Domingo(UASD) en la que obtuvo el título de Licenciado en Historia en 1981; maestría en Educación en el Instituto de Estudios Avanzados de la Fundación Getulio Vargas, Río de Janeiro, Brasil, y en 1992 obtuvo el doctorado en Educación en la Universidad Federal de Río de Janeiro. Ha publicado Los inicios de la colonización en América (1988); Carnaval, cuaresma y fechas patrias (2003); La palabra cocolo: una africana encubierta (2004); Fradique Lizardo. Aporte a la cultura y folklore de la República Dominicana (2005); y Cotui: Villa, cofradía, carnaval y palos (2005), entre otros. Además es profesor en el Instituto Tecnológico de Santo Domingo, y la Universidad Autónoma de Santo Domingo. 